\title{
Influence of post-traumatic status on health-related quality of life among survivors 10 years after the Wenchuan earthquake in China
}

\author{
Liping Zhang ${ }^{1 \#}$, Yu Wang ${ }^{2,3 \#}$, Xinyao Huang ${ }^{2}$, Ma Lan $^{1}$, Hui Ji ${ }^{1}$ \\ ${ }^{1}$ Health and Wellness School, Panzhihua University, Panzhihua, China; ${ }^{2}$ Attached Hospital of Panzhihua University, Panzhihua, China; ${ }^{3}$ Medical \\ School, Panzhihua University, Panzhihua, China \\ Contributions: (I) Conception and design: All authors; (II) Administrative support: None; (III) Provision of study materials or patients: None; (IV) \\ Collection and assembly of data: L Zhang, X Huang, Y Wang; (V) Data analysis and interpretation: All authors; (VI) Manuscript writing: All authors; \\ (VII) Final approval of manuscript: All authors. \\ \#These authors contributed equally to this work. \\ Correspondence to: Ma Lan. Health and Wellness School, Panzhihua University, Panzhihua, China. Email: 443433936@qq.com.
}

\begin{abstract}
Backgrounda China is a country with frequent earthquakes. Beichuan was the epicenter of what was later called the Wenchuan earthquake, which caused nearly $80 \%$ of the houses in the area to collapse, with 8,605 people killed and 9,693 people missing. The aim of our study was to explore the prevalence of post-traumatic stress disorder (PTSD) and its influence on health-related quality of life (HRQOL) among the survivors 10 years after the 2008 Wenchuan earthquake in China.

Methods: A total of 610 survivors from Leigu town in Beichuan County were investigated by a systematic sampling method. Post-traumatic status, HRQOL, and demographic sources were measured by the PTSD Checklist Civilian Version (PCL-C), 36-item Health Survey Short Form (SF-36), and self-questionnaire, respectively.

Results: Ten years after the Wenchuan earthquake, the prevalence of PTSD for survivors was 1.6\%. There were significant negative correlations between survivors' SF-36 scores and the scores of PCL-C. Higher scores in post-traumatic status were associated with a higher rate of poor physical HRQOL, which was lower than the mean score [adjusted odds ratio (OR) $1 / 40.96$ per SD increase, P 1/4 0.001] and mental HRQOL (adjusted OR 1/4 0.93 per SD increase, P 1/4 0.001). The independent contribution of post-traumatic status to the risk for poor physical and mental HRQOL was $4.9 \%$ and $18.7 \%$ respectively.
\end{abstract}

Conclusions: As time has elapsed, the incidence of PTSD has gradually declined after the Wenchuan earthquake. Post-traumatic status was found to influence the health related quality of life of survivors.

Keywords: Post-traumatic status; health-related quality of life (HRQOL); Wenchuan earthquake; survivors

Submitted Dec 14, 2020. Accepted for publication Mar 23, 2021.

doi: 10.21037/apm-21-309

View this article at: http://dx.doi.org/10.21037/apm-21-309

\section{Introduction}

On May 12 2008, a powerful earthquake occurred in the Sichuan Province of Southwest China, with the Wenchuan and Beichuan counties experiencing the worst of the disaster. It was the largest and most destructive of the earthquakes that have hit China since its reformation in 1949. According to reports, 69,226 people were confirmed dead, 374,643 injured, and 18,341 listed as missing. The economic loss of the earthquake was over 845 billion. Sichuan Province experienced the greatest losses, accounting for more than $91.3 \%$ of the total national damages. Beichuan, a county of 100,000 people, was the epicenter of the Wenchuan earthquake, where nearly $80 \%$ of the houses collapsed, 8,605 people were killed, and 9,693 people went missing (1). When a large scale disaster such as earthquake happens, usually Posttraumatic stress disorder (PTSD) would also develop. Our previous study showed that the prevalence of 
post-traumatic stress disorder (PTSD) among the survivors 3 years after the Wenchuan earthquake was $11.2 \%$. It has been 10 years since the earthquake occurred, and it is unclear whether or not the survivors still experience PTSD symptoms and what the prevalence of PTSD in the area is. It can manifest as a series of long-standing and delayedappearance mental disorders that arise from life-threatening emergencies or catastrophic events, the main characteristic behaviors include re-experiencing, avoidance, and hyper arousal, among others (2). Previous studies have found that PTSD usually occurs a few months or even several years after the trauma, about two thirds PTSD patients could recover over time, while others would become more serious, and the posttraumatic state could continue further to affect their cognitive and behavior functions for several years or even longer (3). PTSD not only adversely impacts people's physiology, but also their relationships, work, and social life $(4,5)$. Thus, health-related quality of life (HRQOL) is an essential metric for assessing human health within an individual's embedded life, and takes into account physical health, social relationships, psychological state, and personal beliefs as salient features of the patient's personal environment (6).

A study from Chen et al. revealed that regularly evaluating the post-traumatic symptoms of survivors could provide a scientific basis for the development of community health service (7). We thus reasoned that it was also essential to explore the Wenchuan earthquake survivors' post-traumatic status and HRQOL a few years after the disaster, as a literature search in PubMed retrieved little relevant data. We conducted this study from July 2018 to August 2018 in Leigu town of Beichuan County. The aim of our study was to determine the prevalence of PTSD in the area and its influence on HRQOL of people who have experienced the Wenchuan earthquake 10 years later. The long-term dynamic monitoring of the Post-traumatic stress of the survivors, understanding the degree and dimension of the impact of Post-traumatic stress on the quality of life, taking targeted intervention measures to improve the quality of life of the survivors. We present the following article in accordance with the MDAR checklist (available at http://dx.doi.org/10.21037/apm-21-309).

\section{Methods}

\section{Study design and participants}

A cross-sectional survey was carried out in 2018 in Leigu town of Beichuan County, which was the county most severely damaged by the Wenchuan earthquake. At the time of the study, there were about 2,300 families and 7,700 people in this community. A minimal sample size of 607 subjects was required. A method of systematic sampling according to the household units in this community was adopted. At last, 760 families were selected. The inclusive criteria for participants included the following: (I) had experienced the Wenchuan earthquake in Beichuan county on May 12, 2008; (II) over 13 years old; (III) had lived in Leigu town for at least a month before the investigation; (IV) participated voluntarily in the survey. The exclusive criteria were the following: (I) had mental illness or language barriers; (II) had seriously somatic disease; (III) was absent for three household visits or refused to be interviewed. Most of families in Leigu have three or more family members. In order to ensure the independence of the data set, only one participant within a family was recruited for interview. If a sampled individual was unavailable, the next available individual was sampled. If they had similar symptoms such as depression, anxiety or another psychological problem, they would be excluded. We chose the first host we met in a family. There were 44 families who refused to be interviewed during the three family visits, 79 families who were unable to be contacted directly, and 27 families who were ineligible for the study because of mental and somatic problems. Finally, 610 participants were included in the study. Data were collected via face-toface interview by trained study personnel. The study was approved by the Research Ethics Board of the affiliated hospital of Panzhihua University in February 2018 (No. 102102410191). All procedures performed in this study involving human participants were in accordance with the Declaration of Helsinki (as revised in 2013). All participants provided written informed consent.

\section{Procedure}

Our survey teams comprised psychologists and medical students (from Panzhihua University) and were divided into five small groups. Each small group had one psychologist, three medical students, and one local government staff member. All groups had at least three members who could speak the local dialect fluently. A three-day training course was carried out for the teams by the relevant experts. In addition, a pilot study was conducted in January 2018. Before the assessments, all interviewers were called together to review the questionnaire to ensure a uniform 
understanding of each item. All research data were collected by interviewers through face-to-face interview using structured study questionnaires.

\section{General study questionnaire}

The questionnaire included items on social demographic data and the earthquake-related information. Sociodemographic variables included ethnicity, sex, age, marital status, education level, occupation, and income (monthly). The earthquake-related losses included property damage, personal injury (yes/no), family member injury (yes/no), and the death of family members (yes/no). Property damage was assessed by the following question: "How much property damage did you suffer from the Wenchuan earthquake?" The possible response was either $<10,000$ or $>10,000 \mathrm{CNY}$.

\section{The PTSD checklist-civilian version (PCL-C)}

Post-traumatic stress symptoms were evaluated with the PCL-C, which was developed based on the Diagnostic and Statistical Manual of Mental Disorders IV (DSM-IV) $(8,9)$. The scale has been validated in Chinese populations and is also proven to have excellent reliability and validity, with a Cronbach's alpha coefficient of 0.84 and a split half reliability of 0.65 (10). The PCL-C contains 17 items, and each item is scored from 1 to 5 according to the following values: $1=$ not at all; $2=$ a little; 3 = quite a bit; 4 = extremely; 5 = very extremely. The total scores ranged from 17-85. With a PCL-C score of 38 and 50 as the diagnostic cut-offs, scores in the range of 50-85 indicate more obvious PTSD symptoms, which may be diagnosed as PTSD. Higher scores represent a greater possibility of PTSD. This diagnostic cut-off point (a score of 50) was used in the present study to identity PTSD symptoms (11).

\section{The 36-Item Short-Form Health Survey (SF-36) Questionnaire}

HRQOL was assessed with the Chinese version of the SF36, which was translated from the standard English version of the SF-36, demonstrating satisfactory construct and clinical validity and internal consistency (12). The SF-36 is a generic health survey instrument designed to evaluate HRQOL in both the physical and mental domains (13). The scale consists of 36 items covering eight domains: four in the area of physical health, including physical functioning $(\mathrm{PF})$, physical role functioning (RP), bodily pain (BP), and general health $(\mathrm{GH})$, and four in the area of mental health, including vitality (VI), social functioning (SF), emotional role functioning (RE), and mental health $(\mathrm{MH})$. Both physical and mental health scores have been empirically validated (14). The total score in each of the eight domains ranges from 0 to 100 , where 0 implies the worst and 100 implies the best HRQOL. We used the mean score of physical HRQOL and mental HRQOL as cut-off points to distinguish between good health and poor health (15).

\section{Statistical analysis}

All data were analyzed by statistical software SPSS 17.0 (SPSS, Chicago, Illinois, USA). Descriptive statistics were computed for demographic characteristic variables. Correlational analyses were conducted to verify the relationship of post-traumatic status with HRQOL. Cluster logistic regression were used to explain the contribution of the respective variables, especially post-traumatic status to influence HRQOL-physical and HRQOL-mental health.

\section{Results}

\section{Participant characteristics}

Descriptive statistics on study variables are presented in Table 1. The predominant ethnic population was Han Chinese $(70.8 \%)$, and the majority of participants were male 329 (53.9\%). Subjects were aged between 16 and 87 years, with an average of $48.4 \pm 18.1$ (SD) years. In terms of the marital status, most participants were married (76.6\%), over half of the study population had the education level of primary school and below, nearly $68.2 \%$ of the participants were farmers, and $36.4 \%$ of the participants had family members who had died in the earthquake. Among all subjects, $10(1.6 \%)$ of the participants were identified as probable PTSD cases. The mean of physical HRQOL score was $81.43 \pm 18.34$, while the mean of mental HRQOL score was $82.05 \pm 12.61$.

\section{Associations of post-traumatic status with HRQOL}

There were significantly negative correlations between the scores of HRQOL (physical health and mental health) and PCL-C (Figure 1). That is, physical health scores decreased significantly with the increase of PCL-C scores (the R square quadratic 0.064). Higher PCL-C scores were associated with the lower HRQOL-mental health scores (R 
Table 1 Characteristics of the study participants $(n=610)$

\begin{tabular}{|c|c|}
\hline Variables & $\mathrm{N}(\%)$ or mean $\pm \mathrm{SD}$ \\
\hline \multicolumn{2}{|l|}{ Cluster 1 (social-demographic) } \\
\hline \multicolumn{2}{|l|}{ Area (earthquake before) } \\
\hline Leigu & $329(53.9)$ \\
\hline Old Beichuan & $281(46.1)$ \\
\hline Ethnicity (Han) & $432(70.8)$ \\
\hline Gender (male) & $329(53.9)$ \\
\hline Age (years) & $48.4 \pm 18.1$ \\
\hline$<18$ & $36(5.9)$ \\
\hline $18 \sim$ & $112(18.4)$ \\
\hline $36 \sim$ & $282(46.2)$ \\
\hline$>59$ & $180(29.5)$ \\
\hline Marital status (married) & $467(76.6)$ \\
\hline \multicolumn{2}{|l|}{ Education level } \\
\hline Primary school and below & $343(56.2)$ \\
\hline Middle school & $177(29.0)$ \\
\hline Senior school and above & $90(14.8)$ \\
\hline Occupation (farmer) & $416(68.2)$ \\
\hline \multicolumn{2}{|l|}{ Income (CNY/person month) } \\
\hline$<1,000$ & $192(31.5)$ \\
\hline$>1,000$ & $418(68.5)$ \\
\hline \multicolumn{2}{|l|}{ Cluster 2 (related losses) } \\
\hline \multicolumn{2}{|l|}{ Property loss } \\
\hline Less $(<10,000 \mathrm{CNY})$ & $199(32.6)$ \\
\hline Large (>10,000 CNY) & $411(67.4)$ \\
\hline Injury to self (yes) & $49(8.0)$ \\
\hline Family member injured (yes) & $214(35.1)$ \\
\hline Family member died (yes) & $222(36.4)$ \\
\hline \multicolumn{2}{|l|}{ Cluster 3 (PCL-C) } \\
\hline Post-traumatic status (score) & $26.16 \pm 8.39$ \\
\hline \multicolumn{2}{|l|}{ PTSD } \\
\hline No & $600(98.4)$ \\
\hline Yes & $10(1.6)$ \\
\hline \multicolumn{2}{|l|}{ Outcomes (HRQOL) } \\
\hline Physical health & $81.43 \pm 18.34$ \\
\hline Mental health & $82.05 \pm 12.61$ \\
\hline
\end{tabular}

PTSD, post-traumatic stress disorder; HRQOL, health-related quality of life.

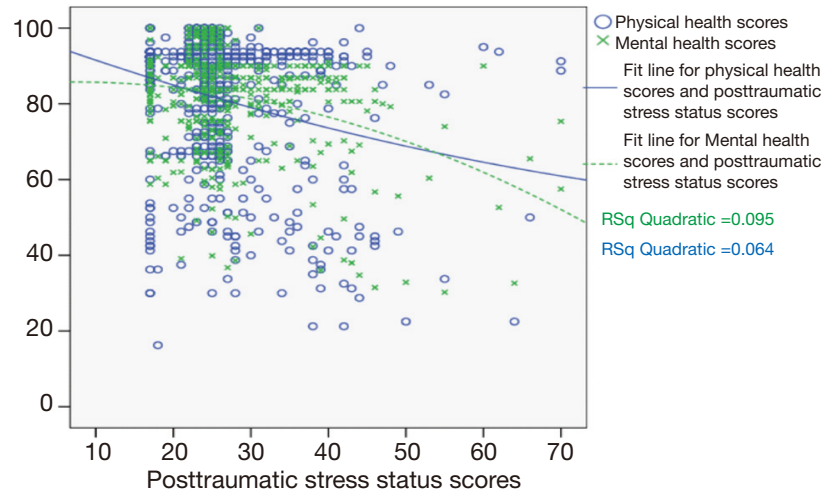

Figure 1 Associations of post-traumatic status scores with physical and mental HRQOL scores. HRQOL, health-related quality of life.

square quadratic 0.095).

\section{Determinants of HRQOL}

\section{HRQOL-physical health}

In the cluster 1 , the independent contribution of social demographic variables was $68.6 \%$ (Table 2). In the cluster 2 (earthquake-related loss variables), the independent contribution of earthquake-related loss variables was $26.5 \%$. In the cluster 3, post-traumatic status was associated with HRQOL-physical health [adjusted odds ratio (OR) 1/4 0.96 per SD increase, P 1/4 0.001]. The independent influence of survivors' post-traumatic status was $4.9 \%$.

\section{HRQOL-mental health}

Among social demographic variables (cluster 1), the independent contribution from social demographic variables was $53.1 \%$ (Table 3). In cluster 2 of the earthquake-related loss variables, the independent influence of earthquakerelated loss variables on the risk of HRQOL-mental health was $28.2 \%$. In cluster 3 , the mental health scores decreased significantly with the increase of PCL-C scores (adjusted OR 1/4 0.93 per SD increase, $P$ 1/4 0.001), the independent contribution of survivors' post-traumatic status was $18.7 \%$.

\section{Discussion}

\section{The prevalence of PTSD 10 years after the Wenchuan earthquake}

Our results showed that the positive rate of PTSD among survivors 10 years after Wenchuan earthquake was $1.6 \%$ 
Table 2 Cluster logistic regression models explaining physical HRQOL according to cluster 1, cluster 2, and cluster 3

\begin{tabular}{|c|c|c|c|c|}
\hline Predictor variables & OR $(95 \% \mathrm{Cl})^{\mathrm{a}}$ & $\mathrm{P}$ & Nagelkerke $\mathrm{R} 2^{\mathrm{b}}$ & Independent contribution (\%) \\
\hline Sex & $0.52(0.34-0.81)$ & 0.004 & & \\
\hline Age & $0.41(0.28-0.59)$ & $<0.001$ & & \\
\hline Occupation & $0.35(0.20-0.62)$ & $<0.001$ & & \\
\hline Total (cluster 1) & & & 0.264 & 68.6 \\
\hline Property loss & $5.14(3.10-8.53)$ & $<0.001$ & & \\
\hline Family member died & $0.64(0.42-0.97)$ & 0.035 & & \\
\hline Injury to self & $0.41(0.20-0.88)$ & 0.021 & 0.366 & 26.5 \\
\hline Total (cluster 3) & & & 0.385 & 4.9 \\
\hline
\end{tabular}

Table 3 Cluster logistic regression models explaining HRQIOL-mental health visits by socio-demographic characteristics according to cluster 1, cluster 2 and cluster 3

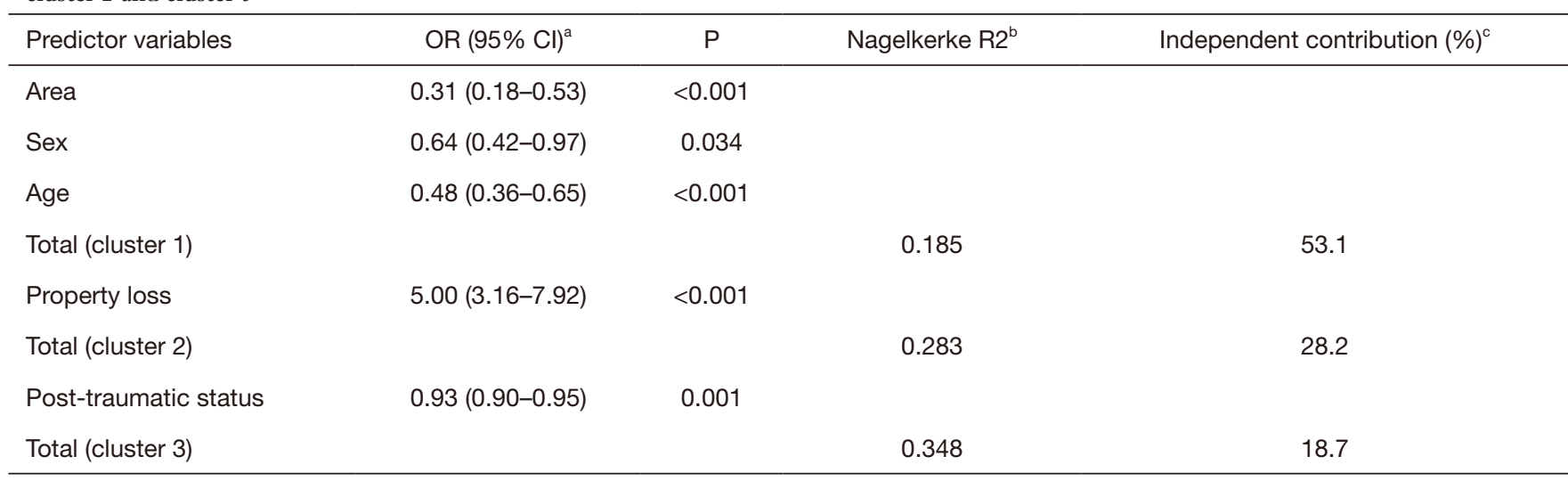

${ }^{\mathrm{a}}$ Odds ratios (ORs) are presented as per SD increase. ${ }^{\mathrm{b}}$ Negelkerke $\mathrm{R} 2$ is the variance of in the dependent variable (mental health) explained by all independent variables included in the regression model. ${ }^{\circ}$ The independent contribution of each cluster of predictors to the variation in mental health was calculated as individual corresponding R2 change/total R2 change (100\%).

(10/610). Through a search of the literature, we found that the positive rate of PTSD among survivors from Leigu town in Beichuan county 2, 3, and 5 years after the Wenchuan earthquake was $12.4 \%, 11.2 \%$, and $8.5 \%$ respectively (16-18). Compared with the previous studies, these results suggested that the positive rate declined gradually as time went on, which was consistent with the study of Giacco et al. (19). This may be related to good social support which had active effects on relieving PTSD. Guo et al.'s research proved that social support may be useful in PTSD intervention and prevention measures for survivors with traumatic experiences in the early stage after an earthquake (20). Survivors were supported with psychological and economic assistance by government and people from all walks of life, which might have contributed to the decline in the positive rate of PTSD and alleviated 
the post-traumatic symptoms.

\section{The effects of PCL-C on physical health}

Our study identified that post-traumatic status was a significant independent determinant of physical and mental HRQOL in survivors 10 years after the Wenchuan earthquake. There were significant negative correlations between physical HRQOL scores and those of PCL-C. Higher scores of post-traumatic status in subjects were associated with greater odds of poor physical HRQOL after controlling for social demographic characteristics and earthquake-related losses. This finding was consistent with those in previous reports (21-24). McMillan et al. showed that organs, including those of the respiratory, cardiovascular, and digestive systems, would change when individuals experienced natural disasters, and that these changes could be adaptations triggered by stress. However, if the stress persisted and exceeded normal limits, a series of physiological health problems may result (25). The research by Dhabhar and Ling also showed that critical life events could cause a sequence of negative physiological experiences, such as a series of changes in physiology, biochemistry, and the immune system $(26,27)$. In addition, stress events might cause a variety of negative stress reactions (27) and a change of endocrine function (28).

\section{The effects of PCL-C on mental bealth}

Higher PCL-C scores were associated with lower mental health scores, and the risk of poor mental HRQOL decreased significantly as PCL-C scores increased. This was consistent with Voiqt et al.'s study (29), in which it was found that 5-hydroxytryptamine (5-HT) has an important role in regulating emotion. Jindal et al.'s research showed that the long-term, chronic, and extreme stress might lead to 5-HT reduced and induced mental illness (30). Meanwhile, Fanq et al. verified that a large amount of glucocorticoids was secreted when people were under severe stress, and that this could cause damage to the hippocampal neurons; furthermore, if the damage continued for many years, this could reduce the volume of the hippocampus, harming learning, memory, and cognitive functions (31). In addition, stress events were found to often lead to the emergence of social anxiety disorder (SAD) (32) and sleep disorders (33), which may seriously worsen patients' quality of life.

\section{Conclusions}

The positive rate of PTSD among survivors 10 years after the Wenchuan earthquake was $1.6 \%$, which was a significant independent determinant of HRQOL among survivors. The findings suggest that post-traumatic status may have a modest influence on physical and mental HRQOL. More attention should be paid to the post-traumatic status of survivors in order to improve their HRQOL after earthquakes and other disasters.

\section{Acknowledgments}

We would like to acknowledge all the research staff (Yan Liu, Ju Yan, Shuang Luo, Yi Lang, Xiaoxi Yang, Ling Yang, Mi Zhang, etc.) who contributed to data collection, and the government of Leigu town in Beichuan County for the support in facilitating the study.

Funding: None.

\section{Footnote}

Reporting Checklist: The authors have completed the MDAR checklist. Available at http://dx.doi.org/10.21037/apm-21309

Data Sharing Statement: Available at http://dx.doi. org/10.21037/apm-21-309

Conflicts of Interest: All authors have completed the ICMJE uniform disclosure form (available at http://dx.doi. org/10.21037/apm-21-309). The authors have no conflicts of interest to declare.

Ethical Statement: The authors are accountable for all aspects of the work in ensuring that questions related to the accuracy or integrity of any part of the work are appropriately investigated and resolved. The study was approved by the Research Ethics Board of the affiliated hospital of Panzhihua University in February 2018 (No. 102102410191). All procedures performed in this study involving human participants were in accordance with the Declaration of Helsinki (as revised in 2013). All participants provided written informed consent.

Open Access Statement: This is an Open Access article distributed in accordance with the Creative Commons Attribution-NonCommercial-NoDerivs 4.0 International 
License (CC BY-NC-ND 4.0), which permits the noncommercial replication and distribution of the article with the strict proviso that no changes or edits are made and the original work is properly cited (including links to both the formal publication through the relevant DOI and the license). See: https://creativecommons.org/licenses/by-nc-nd/4.0/.

\section{References}

1. How much losses does Wenchuan earthquake, cited; Available online: https://wenku. baidu.com/view/ e9f869bfc77da26925c5b03a.html

2. Yang XY, Yang HA, Liu QG, et al. The Research on the Reliability and Validity of PCL-C and Influence Factors. Chinese Journal of health psychology 2007;15:6-8.

3. Liberzon I, Abelson JL. Context Processing and the Neurobiology of Post-Traumatic Stress Disorder. Neuron 2016;92:14-30.

4. Vignato J, Georges JM, Bush RA, et al. Post-traumatic stress disorder in the perinatal period: A concept analysis. J Clin Nurs 2017;26:3859-68.

5. Lawrence KA, Matthieu MM, Robertson-Blackmore E. Civic Service as an Intervention to Promote Psychosocial Health and Implications for Mental Health in Post9/11/01 Era Women Veterans. J Womens Health (Larchmt) 2019;28:1133-42.

6. Skevington SM, Lotfy M, O'Connell KA, et al. The World Health Organization's WHOQOL -BREF quality of life assessment: psychometric properties and results of the international field trial. A report from the WHOQOL group. Qual Life Res 2004;13:299-310.

7. Chen SL, Lee CS, Yen AM, et al. A 10-year follow-up study on suicidal mortality after 1999 Taiwan earthquake. J Psychiatr Res 2016;79:42-49.

8. Psychiatric Association. Diagnostic and statistical manual of mental disorders (4th). Washington, DC: Author; 1994.

9. Foa EB, McLean CP, Zang Y, et al. Psychometric properties of the Post-traumatic Stress Disorder Symptom Scale Interview for DSM-5 (PSSI-5). Psychol Assess 2016;28:1159-65.

10. Pereira-Lima K, Loureiro SR, Bolsoni LM, et al. Psychometric properties and diagnostic utility of a Brazilian version of the PCL-5 (complete and abbreviated versions). Eur J Psychotraumatol 2019;10:1581020.

11. Forbes D, Creamer M, Biddle D. The validity of the PTSD checklist as a measure of symptomatic change in combat-related PTSD. Behav Res Ther 2001;39:977-86.

12. Tan ML, Wee HL, Lee J, et al. The Short Form
36 English and Chinese versions were equivalent in a multiethnic Asian population. J Clin Epidemiol 2013;66:759-67.

13. Wong CKH, Mulhern B, Cheng GHL, et al. SF-6D population norms for the Hong Kong Chinese general population. Qual Life Res 2018;27:2349-59.

14. Moor I, Spallek J, Richter M. Explaining socioeconomic inequalities in self-rated health: a systematic review of the relative contribution of material, psychosocial and behavioral factors. J Epidemiol Community Health 2017;71:565-75.

15. Liao XC. The influencing factors and nursing counter measures of the quality of life for the elderly in the nursing home. Chin J Gerontol 2007;27: 2340-42.

16. Zhang LP, Wang PX, Li YF, et al. Assessment on the mental health status of survivors living in the temporary settlements two years after "5.12" earthquake. Chin J Dis Control Prev 2012;16:674-77.

17. Wang PX, Zhang LP, Li YF, et al. Assessment of Posttraumatic stress disorder of survivors in the" 5.12 " earthquake after three years. J Hyg Res 2013;42:95-98.

18. Zhang LP, Zhao Q, Wang P, et al. Prevalence and risk factors of post-traumatic stress disorder among survivors five years after the "Wenchuan" Earthquake in China. Health Qual Life Outcomes 2015;13:75.

19. Giacco D, Laxhman N, Priebe S. Prevalence of and risk factors for mental disorders in refugees. Semin Cell Dev Biol 2018;77:144-52.

20. Guo J, He H, Fu M, et al. Suicidality associated with PTSD, depression, and disaster recovery status among adult survivors 8 years after the 2008 Wenchuan earthquake in China. Psychiatry Res 2017;253:383-90.

21. Hu T, Xu S, Liu W. A senior high school-based survey on the long-term impact of the Wenchuan earthquake on survivors' quality of life: PTSD as a mediator. Psychiatry Res 2018;270:310-6.

22. McMillan KA, Asmundson GJG, Sareen J. Comorbid PTSD and Social Anxiety Disorder: Associations With Quality of Life and Suicide Attempts. J Nerv Ment Dis 2017;205:732-37.

23. Shieh V, Huang JJ, Wu TG, et al. Rate of psychiatric disorders and associations with quality of life among community members following the Kaohsiung gas explosion: an 18-month cross-sectional follow-up study. Health Qual Life Outcomes 2019;17:7-10.

24. Allen J, Willard VW, Klosky JL, et al. Post-traumatic stress-related psychological functioning in adult survivors of childhood cancer. J Cancer Surviv 2018;12:216-23. 
25. McMillan KA, Asmundson GJG, Sareen J. Comorbid PTSD and Social Anxiety Disorder: Associations With Quality of Life and Suicide Attempts. J Nerv Ment Dis 2017;205:732-37.

26. Dhabhar FS. Effects of stress on immune function: the good, the bad, and the beautiful. Immunol Res 2014;58:193-210.

27. Ling LJ, Wu HP, Liu MJ, et al. The relationship between intraoperative awareness of somatization factors Posttraumatic Stress Disorder and early nursing intervention study. J Clin Nurs 2015;14:7-10.

28. Fu Y, Wang X, Kong W. Hyperhomocysteinemia and vascular injury: advances in mechanisms and drug targets. Br J Pharmacol 2018;175:1173-89.

29. Voigt V, Neufeld F, Kaste J, et al. Clinically assessed posttraumatic stress in patients with breast cancer during the first year after diagnosis in the prospective, longitudinal, controlled COGNICARES study. Psycho-Oncology

Cite this article as: Zhang L, Wang Y, Huang X, Lan M, Ji H. Influence of post-traumatic status on health-related quality of life among survivors 10 years after the Wenchuan earthquake in China. Ann Palliat Med 2021;10(3):3059-3066. doi: 10.21037/ apm-21-309
2017;26:74-80.

30. Jindal A, Mahesh R, Bhatt S. Etazolate, a phosphodiesterase 4 inhibitor reverses chronic unpredictable mild stressinduced depression-like behavior and brain oxidative damage. Pharmacol Biochem Behav 2013;105:63-70.

31. Fanq SC, Schnurr PP, Kulish AL, et al. Psychosocial Functioning and Health-Related Quality of Life Associated with Post-traumatic Stress Disorder in Male and Female Iraq and Afghanistan War Veterans: The VALOR Registry. J Women health (Larchmt) 2015;24:1038-46.

32. Thibaut F. Anxiety disorders: a review of current literature. Dialogues Clin Neurosci 2017;19:87-88.

33. Bavafa A, Khazaie H, Khaledi-Paveh B, et al. The relationship of severity of symptoms of depression, anxiety, and stress with sleep quality in earthquake survivors in Kermanshah. J Inj Violence Res 2019;11:225-32.

(English Language Editor: J. Gray) 